\title{
SMith College
}

\section{Smith ScholarWorks}

Government: Faculty Publications

Government

$11-6-2015$

\section{"Imagine a World in Which": Using Scenarios in Political Science}

Naazneen H. Barma

Naval Postgraduate School

Brent Durbin

Smith College, bdurbin@smith.edu

Eric Lorber

Gibson, Dunn \& Crutcher

Rachel E. Whitlark

Harvard Kennedy School of Government

Follow this and additional works at: https://scholarworks.smith.edu/gov_facpubs

Part of the Political Science Commons

\section{Recommended Citation}

Barma, Naazneen H.; Durbin, Brent; Lorber, Eric; and Whitlark, Rachel E., "'Imagine a World in Which": Using Scenarios in Political Science" (2015). Government: Faculty Publications, Smith College, Northampton, MA.

https://scholarworks.smith.edu/gov_facpubs/18

This Article has been accepted for inclusion in Government: Faculty Publications by an authorized administrator of Smith ScholarWorks. For more information, please contact scholarworks@smith.edu 


\title{
"Imagine a World in Which": Using Scenarios in Political Science ${ }^{1}$
}

\author{
NaAzneen H. Barma \\ Naval Postgraduate School \\ Brent Durbin \\ Smith College \\ ERIC LORBER \\ Gibson, Dunn E Crutcher \\ AND \\ RACHEl E. WhitLaRK
}

Belfer Center, Harvard Kennedy School of Government

\begin{abstract}
A crucial dimension of bridging the gap between international affairs scholarship and policymaking is the generation of substantive, policyrelevant research programs. We describe the use of scenario analysis as a valuable experiential and problem-based technique for developing innovative research ideas in political science. We focus especially on the scholarly and pedagogical potential of scenarios for doctoral students by describing the structured use of scenarios at the annual New Era Foreign Policy Conference. The features of scenario analysis that commend its use to policymakers also make it well suited to helping political scientists generate policy-relevant research programs. Scenarios are plausible and textured stories that help imagine how the future political-economic world could be different from the past in a manner that highlights policy challenges. Scenario analysis can throw into sharp relief overlooked, yet pressing questions in international affairs that demand focused investigation. In turn, the search for answers can shape important research programs geared toward providing actionable clarity in understanding contemporary global issues and challenges.
\end{abstract}

Keywords: scenario analysis, problem-based learning, research agendas, experiential learning, bridging the gap

Over the past decade, the "cult of irrelevance" in political science scholarship has been lamented by a growing chorus (Putnam 2003; Nye 2009; Walt 2009). Prominent scholars of international affairs have diagnosed the roots of the gap between academia and policymaking, made the case for why political science

\footnotetext{
${ }^{1}$ The authors are affiliated with Bridging the Gap, funded by the Carnegie Corporation of New York. We thank Steve Weber and Ely Ratner, who were part of the original team that initiated the New Era Foreign Policy Conference and designed the scenario process we describe here, as well as Jim Goldgeier and Bruce Jentleson for their collaboration and support. We are grateful for their comments and suggestions on this article. The views expressed are our own.
} 
research is valuable for policymaking, and offered a number of ideas for enhancing the policy relevance of scholarship in international relations and comparative politics (Walt 2005,2011; Mead 2010; Van Evera 2010; Jentleson and Ratner 2011; Gallucci 2012; Avey and Desch 2014). Building on these insights, several initiatives have been formed in the attempt to "bridge the gap." ${ }^{2}$ Many of the specific efforts put in place by these projects focus on providing scholars with the skills, platforms, and networks to better communicate the findings and implications of their research to the policymaking community, a necessary and worthwhile objective for a field in which theoretical debates, methodological training, and publishing norms tend more and more toward the abstract and esoteric.

Yet enhancing communication between scholars and policymakers is only one component of bridging the gap between international affairs theory and practice. Another crucial component of this bridge is the generation of substantive research programs that are actually policy relevant-a challenge to which less concerted attention has been paid. The dual challenges of bridging the gap are especially acute for graduate students, a particular irony since many enter the discipline with the explicit hope of informing policy. In a field that has an admirable devotion to pedagogical self-reflection, strikingly little attention is paid to techniques for generating policy-relevant ideas for dissertation and other research topics. Although numerous articles and conference workshops are devoted to the importance of experiential and problem-based learning, especially through techniques of simulation that emulate policymaking processes (Loggins 2009; Butcher 2012; Glasgow 2012; Rothman 2012; DiCicco 2014), little has been written about the use of such techniques for generating and developing innovative research ideas.

This article outlines an experiential and problem-based approach to developing a political science research program using scenario analysis. It focuses especially on illuminating the research generation and pedagogical benefits of this technique by describing the use of scenarios in the annual New Era Foreign Policy Conference (NEFPC), which brings together doctoral students of international and comparative affairs who share a demonstrated interest in policy-relevant scholarship. ${ }^{3}$ In the introductory section, the article outlines the practice of scenario analysis and considers the utility of the technique in political science. We argue that scenario analysis should be viewed as a tool to stimulate problem-based learning for doctoral students and discuss the broader scholarly benefits of using scenarios to help generate research ideas. The second section details the manner in which NEFPC deploys scenario analysis. The third section reflects upon some of the concrete scholarly benefits that have been realized from the scenario format. The fourth section offers insights on the pedagogical potential associated with using scenarios in the classroom across levels of study. A brief conclusion reflects on the importance of developing specific techniques to aid those who wish to generate political science scholarship of relevance to the policy world.

\section{What Are Scenarios and Why Use Them in Political Science?}

Scenario analysis is perceived most commonly as a technique for examining the robustness of strategy. It can immerse decision makers in future states that go beyond conventional extrapolations of current trends, preparing them to take advantage of unexpected opportunities and to protect themselves from adverse exogenous shocks. The global petroleum company Shell, a pioneer of the

\footnotetext{
${ }^{2}$ The phrase "bridging the gap" is usually attributed to Alexander George (1993). Initiatives to bridge the divide between scholarship and policymaking in international affairs include Bridging the Gap, the Tobin Project, and the Scholars Strategy Network.

${ }^{3} \mathrm{NEFPC}$ is the longest standing initiative of Bridging the Gap, which is administered at American University's School of International Service and receives major funding from the Carnegie Corporation of New York.
} 
technique, characterizes scenario analysis as the art of considering "what if" questions about possible future worlds. Scenario analysis is thus typically seen as serving the purposes of corporate planning or as a policy tool to be used in combination with simulations of decision making. Yet scenario analysis is not inherently limited to these uses. This section provides a brief overview of the practice of scenario analysis and the motivations underpinning its uses. It then makes a case for the utility of the technique for political science scholarship and describes how the scenarios deployed at NEFPC were created.

\section{The Art of Scenario Analysis}

We characterize scenario analysis as the art of juxtaposing current trends in unexpected combinations in order to articulate surprising and yet plausible futures, often referred to as "alternative worlds." Scenarios are thus explicitly not forecasts or projections based on linear extrapolations of contemporary patterns, and they are not hypothesis-based expert predictions. Nor should they be equated with simulations, which are best characterized as functional representations of real institutions or decision-making processes (Asal 2005). Instead, they are depictions of possible future states of the world, offered together with a narrative of the driving causal forces and potential exogenous shocks that could lead to those futures. Good scenarios thus rely on explicit causal propositions that, independent of one another, are plausible-yet, when combined, suggest surprising and sometimes controversial future worlds. For example, few predicted the dramatic fall in oil prices toward the end of 2014. Yet independent driving forces, such as the shale gas revolution in the United States, China's slowing economic growth, and declining conflict in major Middle Eastern oil producers such as Libya, were all recognized secular trends that-combined with OPEC's decision not to take concerted action as prices began to decline-came together in an unexpected way.

While scenario analysis played a role in war gaming and strategic planning during the Cold War, the real antecedents of the contemporary practice are found in corporate futures studies of the late 1960s and early 1970s (Raskin et al. 2005). Scenario analysis was essentially initiated at Royal Dutch Shell in 1965, with the realization that the usual forecasting techniques and models were not capturing the rapidly changing environment in which the company operated (Wack 1985; Schwartz 1991). In particular, it had become evident that straight-line extrapolations of past global trends were inadequate for anticipating the evolving business environment. Shell-style scenario planning "helped break the habit, ingrained in most corporate planning, of assuming that the future will look much like the present" (Wilkinson and Kupers 2013, 4). Using scenario thinking, Shell anticipated the possibility of two Arab-induced oil shocks in the 1970s and hence was able to position itself for major disruptions in the global petroleum sector.

Building on its corporate roots, scenario analysis has become a standard policymaking tool. For example, the Project on Forward Engagement advocates linking systematic foresight, which it defines as the disciplined analysis of alternative futures, to planning and feedback loops to better equip the United States to meet contemporary governance challenges (Fuerth 2011). Another prominent application of scenario thinking is found in the National Intelligence Council's series of Global Trends reports, issued every four years to aid policymakers in anticipating and planning for future challenges. These reports present a handful of "alternative worlds" approximately twenty years into the future, carefully constructed on the basis of emerging global trends, risks, and opportunities, and intended to stimulate thinking about geopolitical change and its effects. ${ }^{4}$ As with corporate scenario analysis, the technique can be used in foreign policymaking for

\footnotetext{
${ }^{4}$ National Intelligence Council (2012) is the most recent report, the fifth in the series.
} 
long-range general planning purposes as well as for anticipating and coping with more narrow and immediate challenges. An example of the latter is the German Marshall Fund's EuroFutures project, which uses four scenarios to map the potential consequences of the Euro-area financial crisis (German Marshall Fund 2013).

Several features make scenario analysis particularly useful for policymaking. ${ }^{5}$ Long-term global trends across a number of different realms-social, technological, environmental, economic, and political-combine in often-unexpected ways to produce unforeseen challenges. Yet the ability of decision makers to imagine, let alone prepare for, discontinuities in the policy realm is constrained by their existing mental models and maps. This limitation is exacerbated by well-known cognitive bias tendencies such as groupthink and confirmation bias (Jervis 1976; Janis 1982; Tetlock 2005). The power of scenarios lies in their ability to help individuals break out of conventional modes of thinking and analysis by introducing unusual combinations of trends and deliberate discontinuities in narratives about the future. Imagining alternative future worlds through a structured analytical process enables policymakers to envision and thereby adapt to something altogether different from the known present.

\section{Designing Scenarios for Political Science Inquiry}

The characteristics of scenario analysis that commend its use to policymakers also make it well suited to helping political scientists generate and develop policy-relevant research programs. Scenarios are essentially textured, plausible, and relevant stories that help us imagine how the future political-economic world could be different from the past in a manner that highlights policy challenges and opportunities. For example, terrorist organizations are a known threat that have captured the attention of the policy community, yet our responses to them tend to be linear and reactive. Scenarios that explore how seemingly unrelated vectors of change-the rise of a new peer competitor in the East that diverts strategic attention, volatile commodity prices that empower and disempower various state and nonstate actors in surprising ways, and the destabilizing effects of climate change or infectious disease pandemics-can be useful for illuminating the nature and limits of the terrorist threat in ways that may be missed by a narrower focus on recognized states and groups. By illuminating the potential strategic significance of specific and yet poorly understood opportunities and threats, scenario analysis helps to identify crucial gaps in our collective understanding of global politicaleconomic trends and dynamics. The notion of "exogeneity" - so prevalent in social science scholarship-applies to models of reality, not to reality itself. Very simply, scenario analysis can throw into sharp relief often-overlooked yet pressing questions in international affairs that demand focused investigation.

Scenarios thus offer, in principle, an innovative tool for developing a political science research agenda. In practice, achieving this objective requires careful tailoring of the approach. The specific scenario analysis technique we outline below was designed and refined to provide a structured experiential process for generating problem-based research questions with contemporary international policy relevance. ${ }^{6}$ The first step in the process of creating the scenario set described here was to identify important causal forces in contemporary global affairs. Consensus was not the goal; on the contrary, some of these causal statements represented competing theories about global change (e.g., a resurgence of the nation-state vs. border-evading globalizing forces). A major principle underpinning the

\footnotetext{
${ }^{5}$ We are indebted to Steve Weber for these insights as well as his overall mentorship in the art and practice of scenario analysis.

${ }^{6}$ The leadership team of advanced graduate students in political science who organized the first conference at the University of California, Berkeley, relied on the mentorship of a senior faculty member with extensive professional scenario analysis experience in the policy and corporate realms.
} 
transformation of these causal drivers into possible future worlds was to "simplify, then exaggerate" them, before fleshing out the emerging story with more details. Thus, the contours of the future world were drawn first in the scenario, with details about the possible pathways to that point filled in second. It is entirely possible, indeed probable, that some of the causal claims that turned into parts of scenarios were exaggerated so much as to be implausible, and that an unavoidable degree of bias or our own form of groupthink went into construction of the scenarios. One of the great strengths of scenario analysis, however, is that the scenario discussions themselves, as described below, lay bare these especially implausible claims and systematic biases. ${ }^{8}$

An explicit methodological approach underlies the written scenarios themselves as well as the analytical process around them-that of case-centered, structured, focused comparison, intended especially to shed light on new causal mechanisms (George and Bennett 2005). The use of scenarios is similar to counterfactual analysis in that it modifies certain variables in a given situation in order to analyze the resulting effects (Fearon 1991). Whereas counterfactuals are traditionally retrospective in nature and explore events that did not actually occur in the context of known history, our scenarios are deliberately forward-looking and are designed to explore potential futures that could unfold. As such, counterfactual analysis is especially well suited to identifying how individual events might expand or shift the "funnel of choices" available to political actors and thus lead to different historical outcomes (Nye 2005, 68-69), while forward-looking scenario analysis can better illuminate surprising intersections and sociopolitical dynamics without the perceptual constraints imposed by fine-grained historical knowledge. We see scenarios as a complementary resource for exploring these dynamics in international affairs, rather than as a replacement for counterfactual analysis, historical case studies, or other methodological tools.

In the scenario process developed for NEFPC, three distinct scenarios are employed, acting as cases for analytical comparison. Each scenario, as detailed below, includes a set of explicit "driving forces" which represent hypotheses about causal mechanisms worth investigating in evolving international affairs. The scenario analysis process itself employs templates (discussed further below) to serve as a graphical representation of a structured, focused investigation and thereby as the research tool for conducting case-centered comparative analysis (George and Bennett 2005). In essence, these templates articulate key observable implications within the alternative worlds of the scenarios and serve as a framework for capturing the data that emerge (King, Keohane, and Verba 1994). Finally, this structured, focused comparison serves as the basis for the cross-case session emerging from the scenario analysis that leads directly to the articulation of new research agendas.

The scenario process described here has thus been carefully designed to offer some guidance to policy-oriented graduate students who are otherwise left to the relatively unstructured norms by which political science dissertation ideas are typically developed. The initial articulation of a dissertation project is generally an idiosyncratic and personal undertaking (Useem 1997; Rothman 2008), whereby

\footnotetext{
${ }^{7}$ Steve Weber imparted this concept to us. The phrase is often attributed to Geoffrey Crowther, editor of The Economist from 1938 to 1956.

${ }^{8}$ We note two additional points in order to be self-conscious about possible sources of bias in scenario construction-a suggestion for which we thank two anonymous reviewers. First, the workshop organizers, as a group, do not converge on a particular theoretical paradigm but share a positivist epistemology. This is not, however, a requirement for utilizing scenario analysis; critical theorists have also employed scenario thinking in international relations (e.g., Patomäki 2011). Second, the umbrella project focuses on American foreign policy as an object of study but one of the group's explicit aims was to be as deliberate as possible about building scenarios that are not West-centric. The first set of scenarios was devised for a global scenario project, with workshops held in Haifa, Hong Kong, Geneva, and Singapore-and participants across those four cities did not note any particular biases in the scenarios.
} 
students might choose topics based on their coursework, their own previous policy exposure, or the topics studied by their advisors. Research agendas are thus typically developed by looking for "puzzles" in existing research programs (Kuhn 1996). Doctoral students also, understandably, often choose topics that are particularly amenable to garnering research funding. Conventional grant programs typically base their funding priorities on extrapolations from what has been important in the recent past-leading to, for example, the prevalence of Japan and Soviet studies in the mid-1980s or terrorism studies in the 2000s - in the absence of any alternative method for identifying questions of likely future significance.

The scenario approach to generating research ideas is grounded in the belief that these traditional approaches can be complemented by identifying questions likely to be of great empirical importance in the real world, even if these do not appear as puzzles in existing research programs or as clear extrapolations from past events. The scenarios analyzed at NEFPC envision alternative worlds that could develop in the medium (five to seven year) term and are designed to tease out issues scholars and policymakers may encounter in the relatively near future so that they can begin thinking critically about them now. This timeframe offers a period distant enough from the present as to avoid falling into current events analysis, but not so far into the future as to seem like science fiction. In imagining the worlds in which these scenarios might come to pass, participants learn strategies for avoiding failures of creativity and for overturning the assumptions that prevent scholars and analysts from anticipating and understanding the pivotal junctures that arise in international affairs.

Of course, policy relevance is not enough. A research topic must also contribute to the political science literature, both theoretically and empirically, be tractable, and rely upon robust social science methodology. Through the structured and focused comparative discussion of the scenarios, participants are guided through a process for generating problem-based research questions that are particularly amenable to the application of mid-range theory and thus well suited to dissertation or other early research agendas. The political science discipline has established practices for defining new puzzles within the bounds of existing research. The scenario analysis process we describe here is a way to articulate such puzzles as well as new research programs by focusing on the core questions that emerge when imagining different ways in which the future might unfold.

\section{Scenario Analysis at the New Era Foreign Policy Conference}

The New Era Foreign Policy Conference brings together, through a competitive application and selection process, a select group of Ph.D. candidates and postdocs in the field of international affairs. ${ }^{9}$ The goals of the conference, which has been held annually since 2006, are threefold: (1) to build a network of Ph.D. students who are interested in conducting policy-relevant research on US foreign policy and international politics, (2) to invigorate the foreign policy community with fresh ideas and promising new avenues of research, and (3) to equip a new generation of international affairs scholars with the tools for conducting and disseminating policy-relevant research. In pursuit of these ends, NEFPC participants employ scenarios to imagine and assess contemporary medium-term challenges and opportunities in international affairs. In contrast to the standard, paper-based academic conference oriented toward presenting research results, the workshop format places a premium on unconventional thinking and idea generation and has proven valuable as a way to identify new policy-relevant research programs.

\footnotetext{
${ }^{9}$ Based on our experience in running such scenario exercises, a relatively small group is necessary for the success of the intensive, collaborative process described below. The group was restricted to 15-18 participants annually until 2014 when it was slightly expanded in order to accommodate growing interest in the conference.
} 
Over two days, NEFPC takes participants through four main sets of activities, interspersed with professional development opportunities. ${ }^{10}$ First, an introduction to the use of scenarios as an analytical tool is conducted by a faculty member associated with Bridging the Gap. This session emphasizes the value of using structured approaches for creative thinking and sets the ground rules for engaging in scenario analysis. Second, small breakout groups engage in two rounds of facilitated and focused scenario discussions, such that each participant is immersed in two of the three scenarios written for NEFPC. Third, all of the participants work together through a facilitated exercise designed to cross-fertilize the unique scenario experiences. This session centers on generating ideas through a structured, focused comparison of the different breakout groups' interpretations of each scenario. Finally, the last session of the workshop is spent collectively articulating more cogently the potential research questions that have emerged from discussion and organizing the participants into groups interested in pursuing these as active research projects. By the conclusion of the workshop, we have created a network of like-minded junior scholars interested in policy-relevant political science, while also helping participants develop and explore innovative and policy-relevant research agendas. We now describe in more detail the two core experiential learning and knowledge creation elements of NEFPC: scenario analysis and the subsequent generation of research ideas through cross-fertilization.

\section{The NEFPC Scenario Analysis Process}

Scenario analysis is at the heart of the NEFPC process. Each scenario is presented to the participants as a one-page, single-spaced write-up that conveys important elements of the world of the scenario. ${ }^{11}$ This section utilizes the "Power to the People" scenarios from the 2007 workshop to convey the content of the scenario process (see Appendix for the full "Power to the People" scenario). The introductory section is the high-level concept, which offers-in broad-brush strokes-a glimpse into the world of the scenario. This part helps participants familiarize themselves with the dynamic contours of the new world. "Power to the People" begins with the following high-level concept:

[T] he world of 2012 is seeing new and dramatic forms of political reorganization. Technology and culture together enable the deconcentration and decentralization of power, simultaneously challenging conceptions of the international community and traditional international organizations, and undermining and replacing the functions of national governments with new experiments at the national, regional, and local levels.

Participants are thus invited to envision a world of rampant political change, as new lines of organization develop around culture and technology instead of around strong, centralized nation-states.

The second part of the scenario is the driving forces section, which describes the currents and elements that shape this world. This section highlights causal trends, significant developments and breaks from the past, and other important features of the scenario. These details allow participants to add substance to the snapshot offered in the high-level concept, including the identification of currencies of power, relevant commodities, economic strategies, key actors, and suggestions of

\footnotetext{
${ }^{10}$ The scenario-based core of NEFPC is interspersed with a variety of networking opportunities with senior scholars, workshop alumni, and foreign policy experts, as well as professional development sessions, where participants learn about professional opportunities, fellowship competitions, writing for a policy audience, and fundraising for policy-relevant research.

${ }^{11}$ The three scenarios and two templates that guide the scenario process are distributed to the participants prior to the workshop.
} 
lines of both cleavage and cohesion. In exploring the driving forces, participants discuss explicitly the competing or complementary hypotheses and various causal logics that underpin the scenario.

Once the participants have been fully immersed in the logical narrative of the scenario, the third component-the deepening phase-explores an exemplary event, and outlines a number of other observable implications within the contours of the scenario. The significant event of "Power to the People" occurs as "extremely rich individuals from around the globe" step to the fore to confront the most recent case of genocide, "citing the unwillingness of the international community to act." They organize to design, fund, and deploy a privately financed peacekeeping operation to the Sudan in order to enforce a cease-fire. This is significant in that it demonstrates the new organizational contours of this world, as people step in to fulfill the traditional governance obligations of states.

An important tenet of scenario analysis is that " $[\mathrm{w}]$ hat happens at a scenario's horizon date is not as important as the storyline's clarity of logic and how it helps open the mind to new dynamics" (Wilkinson and Kupers 2013, 6). Indeed, it has not been unusual for participants to find elements of the scenarios implausible at first, and a key function of the facilitators is to help participants move past any initial skepticism. ${ }^{12}$ Moreover, we have seen elements of each scenario realized in contemporary international affairs. For example, while "Power to the People" today closely resembles dynamics associated with the Arab Spring of 2011, the scenario was initially designed in 2007. Similarly, the "Sick, Sick World" scenario developed in 2007 on the basis of contemporary trends posited a global financial crisis set off by the bursting of the housing market in the United States that, in turn, led to a period of relative decline for the Western world. Several participants at the initial NEFPC-and at four related global workshops ${ }^{13}$ - expressed deep skepticism about the plausibility of such a crisis. In a testament to the value of the scenario process, participants who experienced scenarios such as these were among the first to analyze the global dynamics of situations that later surprised and engaged policymakers around the world. Yet the scenario is a tool to facilitate creative thinking, not a predictive end in and of itself. More important than any prescience is the value of thinking about unfamiliar futures that may have roots in the contemporary system.

The scenario analysis breakout sessions proceed in two parts, with the facilitators using poster-sized templates to generate discussion and debate among the participants and graphically capture the world of the scenario and the questions it raises. ${ }^{14}$ First, we focus on collectively understanding the scenario (see Figure 1). Here the participants discuss the most important aspects of the scenario and begin to engage intellectually with the changes that are said to have occurred between the present day and the future world. While examining "Power to the People," for example, participants might note the development of nontraditional cultural and kinship networks along both subnational and ethnic lines. Whereas states were once able to perform the basic functions of governance, now, unable to do so, they outsource to nontraditional actors-private sector security organizations, a variety

\footnotetext{
${ }^{12}$ The quality of the scenario-based approach depends on the caliber and enthusiastic participation of the participants as well as on skilled facilitation. NEFPC facilitators are experienced workshop alumni who have been trained by the organizers in guiding scenario analysis sessions and capturing the discussion using the templates. They are also prepped with strategies for managing participants who are initially inclined to challenge the scenario itself or get locked into ideological arguments about it.

${ }^{13}$ In our first year (2006), we conducted a series of workshops with scholars and policymakers in Haifa, Hong Kong, Geneva, and Singapore to explore how various regional actors perceived the challenges facing the United States differently.

${ }^{14}$ Emily Shepard designed these templates for our use in collaboration with the NEFPC team. We are grateful for her permission to replicate them here.
} 


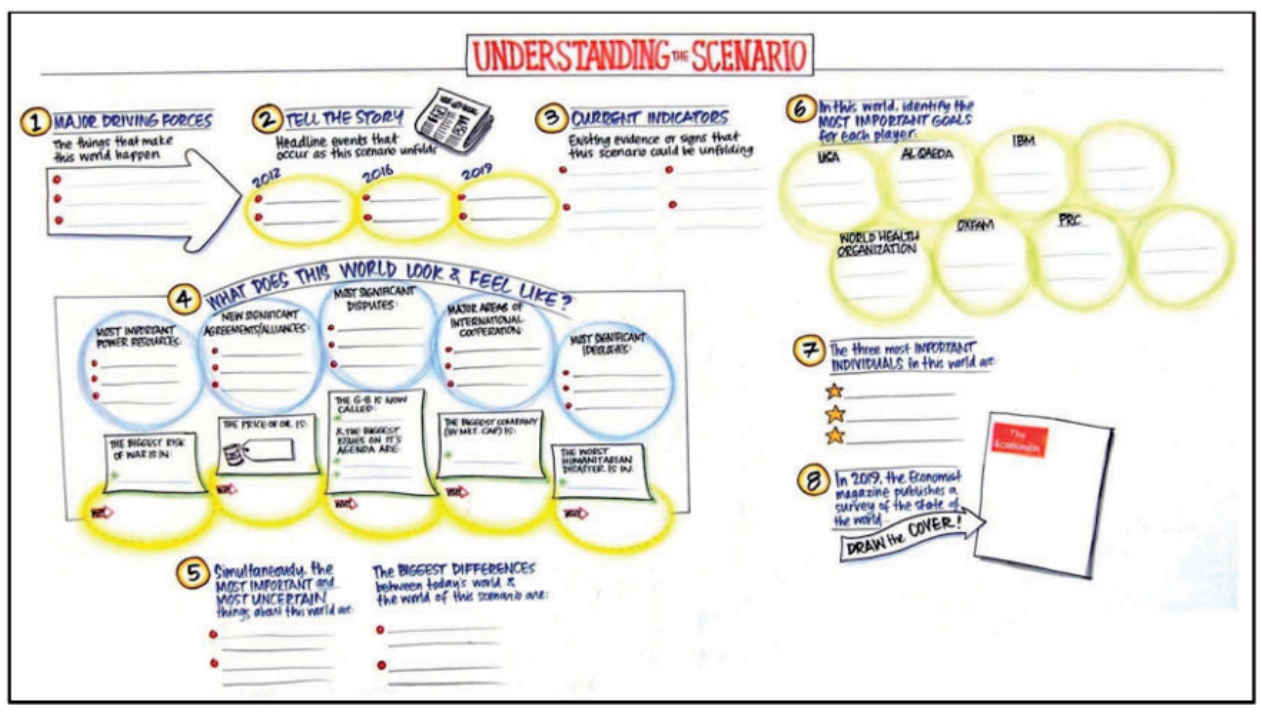

Figure 1. Understanding the scenario discussion template.

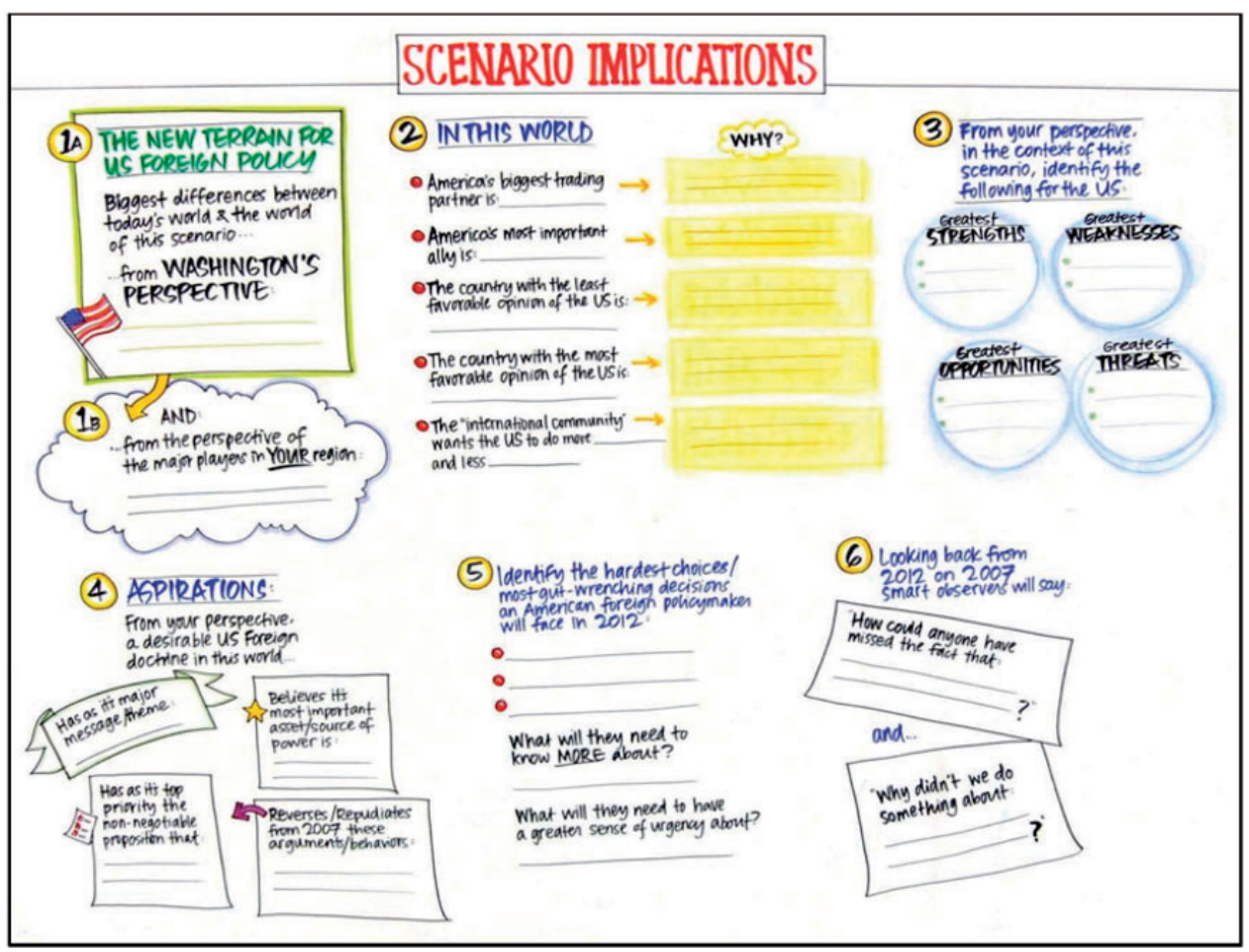

Figure 2. Scenario implications discussion template.

of humanitarian NGOS, and mega-philanthropists with global designs. In exploring these and other notable dynamics described in the scenario, participants find forms of organization and networking that are radically different from the state-led world to which we as analysts have become accustomed. 
Second, we collectively explore the implications of the changes discussed in the scenario and the developments that might follow (see Figure 2). The discussion is designed to probe who benefits and who is disadvantaged in the scenario and to consider the role of the United States and other key actors given the new constraints and opportunities embedded in the language of the scenario. ${ }^{15}$ Thus, in "Power to the People," participants might ponder how the United States would respond to the groundswell of populism in the Middle East, how international organizations might react to the outsourcing of traditional statist roles, and how influential individuals will interface with those states that are able to maintain their power and centralized control.

As discussed above, the scenario templates represent a carefully formulated set of questions used to examine the three scenario cases. In turn, as we discuss next, they help to facilitate a structured comparison of the alternative worlds and aid in the subsequent generation of research agendas.

\section{Cross-Fertilization and the Generation of Research Programs}

Following the individual scenario discussions held in breakout groups, the workshop participants collectively engage in a process of cross-fertilization to develop new ideas for research. The participants identify new or noteworthy themes that emerged in the scenario conversations and then, led by the facilitators, group these issues of interest into broad sets of research questions. Typically, this is a relatively organic process: as participants begin brainstorming about emerging themes or tensions from across the scenarios, the facilitators also encourage the group to focus on how political science might help investigate these topics and provide novel answers. In essence, this stage guides a problem-based method of inquiry: it begins with puzzles emerging from the forward-looking scenarios, moves to a collective discussion of the dozens of discrete ideas the scenarios generate, and then helps to shape these into research topics.

The cross-fertilization stage begins with participants exploring the comparative versions of the scenario template posters. They are asked to identify surprising or puzzling elements, important matters common to all three scenarios, or noteworthy points of contrast between two versions of one scenario or across the different scenarios. Hence, participants consider what factors appear to be significant no matter which alternative world unfolds, as well as differentiating, in a structured manner, among the core causal forces leading into one alternative future versus another. Providing very wide latitude in terms of what the participants find noteworthy and valuable for discussion produces many individual threads of discussion. ${ }^{16}$ Through the exploration of the scenarios, participants have been encouraged to question their assumptions and to think creatively about possible future states of international affairs where these preconceptions might no longer hold. The traditional academic experience trains students to think within the parameters of disciplinary debates, be they theoretical, empirical, or methodological. The NEFPC scenario exercise is intended to create an intellectual environment in which imaginative thinking outside the traditional strictures is encouraged. The scenarios and the process in which they are embedded serve as a tool for identifying new areas of academic inquiry, which are now discussed as much as participants wish.

The final session of NEFPC is designed to take the broad lines of inquiry that have been identified and narrow them into more feasible research projects. At

\footnotetext{
${ }^{15}$ While our project has maintained a focus on the US role in the world, this is not a necessary component of the scenario process. It can easily be adapted to center on one or more different states, institutions, or other actors, including the interaction of multiple actors within a given set of scenarios.

${ }^{16}$ As a practical matter, we have hung the scenario posters around the workshop room walls or attached them to large easels. We have also used large easel pads for the participants to note their observations in short phrases that then serve as the focal points of group discussion.
} 
this point in the workshop, the scenarios themselves are no longer central-they have served as the analytical scaffolding upon which the subsequent discussion about research programs rests. This final step focuses participants back on the political science discipline, but with fresh ideas to bring to their scholarship. Participants are now less concerned about the imagined futures and more about the theories and tools of social science and how best to leverage these in the construction of new research programs. We can now focus on what the scenario process has illuminated-key independent and dependent variables, new causal relationships, previously unexplored phenomena, and familiar phenomena seen in a new light. We can recognize the possibility of divergence from anticipated trend lines and think beyond existing paradigms or consider how to redeploy standard ones in a new way. And we can discuss how to connect these issues to existing political science scholarship and tackle the puzzles they pose with rigorous analytical methods.

Thus, for the final session, the workshop facilitators synthesize the issues arising from the cross-fertilization session into three to four baskets of topics under broad rubrics. In the past, these themes have included such issues as the role of technology in facilitating governmental change, new methods of autocratic repression, and the changing nature of public goods provision in the international system. The facilitators then lead participants in discussing these thematic threads, working together to distill the raw insights into discrete research topics and questions. For example, one discussion of "new methods of autocratic repression," led to the questions of whether and how autocratic regimes learn from the success and failures of other regimes' repressive actions. As the group delves into each thematic basket and sharpens the ideas into narrower and more specific research questions, it also considers how political science scholars would answer such questions in terms of both substance and method. In considering the question about autocratic learning, the group discussed what types of research methods might be useful, what scholarship currently exists on the topic, and what data exist to give participants a starting point for their own projects. After working through each research question within each topical thread, the participants and facilitators have a better sense of the range of specific research questions they can ask, as well as different approaches they can adopt to answer them in a robust and policy-relevant way.

At the close of the research question-generation session, the facilitators organize panels for the following year's International Studies Association (ISA) annual meeting - a preeminent conference for scholars of international affairs. These panels are organized around the broad themes discussed; there are usually two to four panels per year, with each panel consisting of three to five papers based on the research questions developed at the workshop. ${ }^{17}$ Participants volunteer to develop the panel submissions-including the task of seeking out more senior chairs and discussants to ensure helpful feedback on the research-and to write the individual papers for the panels. At the following year's ISA meeting, workshop alumni present the resulting research papers on these panels. Thus NEFPC keeps an eye on ensuring that participants turn their research questions into publishable papers that can both boost their academic careers and potentially inform the policy community.

\section{Benefits of the New Era Foreign Policy Conference Scenario Approach}

The scenario analysis workshop experience helps participants become better scholars by acquiring a tool to generate fresh, policy-relevant research ideas and

\footnotetext{
${ }^{17}$ At the 2013 ISA meeting in San Francisco, for example, panels explored public goods provision in the international arena, the causes and consequences of economic stagnation and resurgence, and the implications of rapidly developing and global technology for international politics.
} 
produce research on that basis. NEFPC also offers participants the opportunity to cement professional skills and connect to a network of like-minded peers. It thus offers a number of important assets for scholars who hope to work at the nexus of international relations scholarship and policy relevance.

In the first instance, the scenario-based approach develops students' ability to identify interesting questions by encouraging them to think creatively about what the world may look like in a few years and asking what we would need and want to know about that world. In turn, the NEFPC experience teaches them how to narrow down significant insights into researchable questions. For example, if the scenario world we discuss is one populated by a growing number of autocratic regimes that learn from each other, participants might ask how-and under what conditions-autocratic regimes have learned historically as a way to shed light on an issue that might become relevant in the near future. This question is interesting to the policy community, researchable from a practical perspective, speaks to an important debate in the international relations literature, and could easily serve as the basis for a journal article or a dissertation.

Conversations like those facilitated at NEFPC are important given that it is not self-evident what makes for an acceptable and feasible research question in political science. Few doctoral students begin their studies with inherent knowledge concerning the requisite breadth and depth of scholarly projects. Rather, students learn through exposure to the norms and conventions of the discipline. Exploring substantive topics and ways to analyze them in this experiential setting allows junior scholars to learn from one another, with the guidance of a handful of more seasoned academics, and to develop new analytical and research skills. NEFPC thus openly introduces another layer of disciplinary socialization through a process we view as complementary to the core training received by students in their coursework and home departments. Consequently, we do not compare the success of this program to other types of training but rather view it as yet another way to help young scholars produce rigorous, policy-relevant scholarship.

Second, the scenario-based approach helps facilitate the production of scholarship by assembling conference panel proposals that explore some of the research questions developed during the workshop and by inspiring graduate students to develop tangible research ideas they can turn into publications. Over the past ten years, NEFPC alumni have successfully proposed and presented about twenty ISA panels, with a total of more than seventy papers. Many of these papers have been well-received, ${ }^{18}$ and graduate students and junior faculty have published articles with both academic and policy relevance based on the ideas developed at the workshop (Barma, Ratner, and Weber 2007, 2013; Barma and Whitlark 2013; Bleek and Lorber 2014; Feaver and Lorber 2014). By guiding participants through a process for generating researchable ideas and turning those ideas into conference papers, pieces of dissertations, and possible publications, NEFPC helps prepare these young scholars for their careers as professional political scientists.

Third, some of the ideas developed at NEFPC and refined through the academic publication process have been transmitted to policymakers. A core theme that emerged at the first workshop, for example, was the increasing power and interconnectivity of the emerging economies in the non-Western world. Building on that insight, three NEFPC founders wrote two policy-oriented pieces on what they dubbed the "World Without the West" in The National Interest (Barma, Ratner, and Weber 2007, 2013), which attracted attention in policy circles

\footnotetext{
${ }^{18}$ For example, Seva Gunitsky, a 2009 NEFPC alumnus, received Honorable Mention for the Carl Beck Award at the 2010 ISA annual meeting for his paper on power transitions and normative change. The award is presented to the best paper authored by a graduate student at the annual meeting.
} 
(National Intelligence Council 2008) ${ }^{19}$ They also worked with other colleagues to produce an empirical investigation of the concept that appeared in a peer-reviewed scholarly journal (Barma et al. 2009). Another participant developed a workshop-inspired project on the difficulty of unwinding economic sanctions and the challenges this poses for the successful use of coercive diplomacy. He co-authored an article on the subject (Feaver and Lorber 2014) and then presented his work to former NEFPC participants working in government during the Obama Administration's Fall 2014 push toward an interim agreement on Iran's nuclear program. A number of workshop alumni have held senior positions in the national security decision-making apparatus, serving for example on the National Security Council as Deputy National Security Advisors and as staff on the Senate Foreign Relations Committee. Others hold senior positions at major foreign policy think tanks. Through the NEFPC network, participants are able to disseminate their ideas directly to these policymakers.

Fourth, NEFPC builds a network of political scientists interested in policy-relevant issues. Many of the graduate students and young faculty who participate in the workshop have interests in similar topics. Bringing together these junior scholars early in their careers provides them with the opportunity to know, learn from, and work with others who will be their colleagues throughout their careers, including important connections with more senior scholars. The network has already produced collaboration in many areas, as indicated by several of the research projects and publications mentioned above. In addition, as part of this network, participants engage with like-minded scholars who believe in the role that academics have to play in informing foreign policy decision making. Although in some political science departments today discussing this goal openly is taboo-especially for a doctoral candidate or untenured scholar-NEFPC and Bridging the Gap support, encourage, and embrace it.

This network expands overseas as well. A related Bridging the Gap project employing scenarios, the New Era International workshop, took place in December 2013 at the Singapore Management University. Over two days, seventeen scholars and policy analysts from across Asia used a focused set of scenarios to explore the provision of public goods in Southeast Asia, with a particular emphasis on the respective roles played by the United States, China, and the Association of Southeast Asian Nations, or ASEAN. The three scenarios for this workshop posited different power trajectories for each of these actors. Through our discussion and comparison across these possible futures, we considered how the regional provision of two types of public goods-infectious disease prevention and energy governance-could develop, and who might be positioned to positively influence this evolution. While the research outputs from this workshop are still developing, participants expressed great enthusiasm for the scenario process and the insights it provided.

Fifth, given the significant amount of interest among major grant organizations for projects that pursue policy-relevant research, NEFPC helps to position participants with an increased chance of receiving external support, an important criterion and metric for success in academia. Over the past few years, the Smith Richardson Foundation, the Stanton Foundation, the Carnegie Corporation, the MacArthur Foundation, and the Minerva Research Initiative, among others, have given millions of dollars to projects that utilize political science methods to explore policy-relevant topics-and numerous workshop alumni have competed successfully for these funding sources.

\footnotetext{
${ }^{19}$ The National Intelligence Council's Global Trends 2025 report included a scenario entitled "A World without the West" (National Intelligence Council 2008).
} 


\section{Teaching with Scenarios}

The observed benefits of scenario analysis for scholarly research are echoed in many ways by its use in teaching. ${ }^{20}$ The method is extremely flexible because instructors can tailor both the content of the scenarios and the analytical process to accomplish learning objectives across many different types of curricula. And while the scenario process described above was designed specifically for international relations and foreign policy analysis within the discipline of political science, the model is certainly applicable elsewhere, including in other fields of social science. Here, we consider the possible uses of scenarios for teaching at the doctoral, master's, and undergraduate levels.

\section{Doctoral}

We have already highlighted some of the pedagogical benefits of scenario analysis for doctoral students. Not only can this approach help students identify new and interesting research topics, it can also provide an opportunity to consider how the conceptual and theoretical frameworks of their discipline interact with real-world problems and policies.

For students early in their doctoral programs, scenarios that cover a broad range of issues-such as those presented above-might be most helpful for identifying new research agendas and even dissertation topics. Indeed, several NEFPC participants have noted the value of the workshop for "road testing" the theories covered in their international relations and comparative politics field seminars. A one- or two-week scenario exercise would be a valuable addition to many such courses, both as a way to apply and contrast elements of the existing literature and as an opportunity to identify interesting topics requiring further exploration. For later stage candidates, the process could be helpful for finding a new project beyond one's dissertation.

In courses with a narrower focus, scenarios could be written to provide analytical leverage on the politics of a specific region, topic, or set of actors. Consider, for example, the debate over nuclear proliferation in international relations. Scholars such as Kenneth Waltz have argued that proliferation can make conflict less likely by increasing the number of states with strong deterrent capabilities (Sagan and Waltz 2003). Others disagree. Scott Sagan, for example, has noted that the conditions for stable deterrence-including symmetrical nuclear forces and second-strike capabilities, and the ability to avoid accidental war-are difficult if not impossible to achieve in most contexts (Sagan and Waltz 2003). Scenarios can be employed to understand better the nuances and implications of this debate. Students might, for example, examine these arguments through a set of scenario futures that describe different outcomes in the Pakistan-India relationship, including nuclear conflict, conventional conflict, and no conflict. Through the process of "deepening" the scenarios, students would be challenged to identify different causal pathways that might lead to each outcome, as well as which factors seem most and least influential. Such an approach would provide an opportunity to consider different methods for studying the topic, such as the identification of necessary and sufficient conditions for obtaining a certain result. This effort would also require students to apply their empirical knowledge of nuclear force structures and regional dynamics to a more general theoretical debate. A similar approach could be used to explore varied futures relating to development trajectories, regional integration dynamics, the politics of energy and natural resources, or almost any other topic of interest to scholars of international relations, comparative politics, or other social science subfields.

\footnotetext{
${ }^{20}$ Note the distinction between our use of the term scenario and that employed in many ethics courses, in which students are asked how they would respond to a narrowly defined hypothetical situation or dilemma (cf. Weber 1992; Wielhouwer 2004).
} 
In addition, exposure to a variety of pedagogical techniques in a Ph.D. program can help students when they become teachers themselves. On the job market, students will be asked to demonstrate that they are prepared to bring innovative and effective techniques into their own classrooms. Scenario analysis is thus a useful addition to a student's teaching toolbox.

\section{Master}

Scenario analysis is an especially useful tool for instructors in public policy, public administration, and other professionally focused master's programs. These programs place a heavy emphasis on connecting theory to practice, and have long employed case studies, role-playing exercises, and other hands-on techniques for training their students. Scenarios provide another way for professional students to develop their analytical and practical skills through problem-based learning. In addition to the intellectual benefits described in the sections above, the scenario process can give master's students a chance to serve as facilitators, rapporteurs, and discussion leaders, depending on the instructor's objectives for the course. Scenario exercises can also couple well with various communication assignments-such as policy memoranda, briefing books, and formal presentationsthat are well suited to the professional goals of master's-level students. Given the increasing use of scenarios throughout the public, private, and nonprofit sectors, such training will also be appealing to a wide range of employers.

\section{Undergraduate}

Using scenarios in undergraduate courses presents a unique set of challenges and rewards. Most undergraduate students are neither looking to start major research projects nor seeking to develop a specific set of skills for professional policy work. Moreover, undergraduates often do not have the requisite breadth of conceptual and historical knowledge to develop a full understanding of complex scenarios and their implications. The goals and methods of an undergraduate scenario exercise will likely be different from those at the graduate level.

Even so, scenarios can be a very valuable tool in the college-level classroom. For example, scenario analysis can be used to ask "what comes next?" at the conclusion of survey courses in international relations and US foreign policy. In such classes, students are often particularly susceptible to believing that the world will continue to evolve along current trend lines-e.g., that nonstate actors will be increasingly important in international affairs, or that the US-China relationship will define global politics in the twenty-first century. Well-crafted scenarios propose alternative dynamics that force students to question their assumptions, ideally by bringing related course content into their analyses. Importantly, a basic scenario exercise does not require the detailed logistics or infrastructure (formal templates, guided breakout sessions, etc.) employed at the workshop described above. Rather, an instructor can try out the approach by following three basic steps: first, write up a set of one to three one-page scenarios describing different possible futures; second, give students time to consider and discuss these in small groups, either during or outside of class; and, third, facilitate a discussion of interesting questions and observations that the scenarios raise, including cross-fertilization across different scenarios. With experience, the technique can then be adapted to be more complex and to meet additional learning objectives.

Finally, a growing body of research finds that students learn best in a diverse and active learning environment (Brown and King 2000; Burch 2000; Asal 2005; Glasgow 2012). The scenario approach adds another lens through which to analyze complicated political dynamics in a fun, interactive, and experiential way. Scenarios also accord well with the "flipped classroom," in which students learn facts and concepts outside the classroom-such as through recorded lectures or 
podcasts-and then apply these critically during class. For example, the "Power to the People" scenario described above could be used to address readings or other preparation on social movements, democratization, specific regional dynamics, or a host of related topics. In this way, scenario analysis may be most fruitful in the undergraduate classroom when it is used to explore and test material that has already been covered, rather than to introduce new material.

\section{Conclusion}

Crucial dimensions of bridging the gap between international affairs scholarship and policymaking include the production of substantive, policy-relevant research programs and the equipping of a new generation of political science students with the skills to connect theory to practice. This article has made the case that scenario analysis is a valuable experiential and problem-based technique for the political science discipline, bringing both scholarly and pedagogical benefits. Because scenarios can aid political scientists in imagining plausible alternative worlds in the future, applying this technique to contemporary international affairs offers a structured, comparative process for generating research agendas on otherwise overlooked and crucial issues. In addition, because this analytical exercise encourages identifying these issues now-well before decision makers are likely to confront them-it enables political scientists to begin pursuing the necessary research to provide policymakers with empirically robust and useful answers to important policy questions that will become significant down the road.

One aim in deploying the process we have described here is to accelerate innovation in policy-relevant political science scholarship by shifting mental maps and thereby illuminating new and essential areas of inquiry. Scenario analysis can be an invaluable aid to scholars in asking questions that are not being asked in policy circles, building middle-range theory to propose answers to those questions, and then communicating the answers to decision makers in ways they can use. Intended to complement traditional methods of political science training, the New Era Foreign Policy Conference aims to equip an emerging cohort of graduate students and junior scholars with the tools to incorporate the kind of thinking that scenarios provoke as a central ingredient of their scholarship. This undertaking is hence a two-sided statement about bridging the gap. It embraces the value of immersion in contemporary international affairs to the political science discipline, in the belief that policy relevant research contributes to the overall diversity of the field without diluting its epistemological commitments. It also takes seriously the goal of policy relevance as one important metric of the quality of scholarship, in the belief that political scientists are well placed to inform and enliven public debate. For, in the end, we at Bridging the Gap feel that it is the collective responsibility of our discipline to engage with and contribute to the public sphere. Scenarios and the workshop model described here provide one avenue to that end.

\section{Appendix: "Power to the People" Scenario}

1. The world of 2012 is seeing new and dramatic forms of political reorganization. Technology and culture together enable the deconcentration and decentralization of power, simultaneously challenging conceptions of the international community and traditional international organizations, and undermining and replacing the functions of national governments with new experiments at the national, regional, and local levels.

2. Various groups in the world have strengthened their organization around nonnation-state centric forms of governance such as cross-national cultural and kinship networks and subnational ethnic splinter groups. 
- Preferential economic arrangements, long opposed by liberal internationalists, are increasingly common and legitimate. They are not regional (i.e., delineated by geography) so much as they are cultural and ethnic (delineated by identity politics, such as technology-enabled kinship networks; e.g., the Chinese bamboo network, and hawala financing in the Islamic world).

- States in some parts of the world are increasingly unable to provide basic governance functions to their populations and are de facto "outsourcing" those functions to a variety of other actors, including private sector security organizations, humanitarian and health NGOs, and mega-philanthropists with global agendas.

3. Citing the unwillingness of the international community to act in stopping ongoing genocide, a collection of extremely rich individuals from around the globe (Richard Branson, Lakshmi Mittal, and George Soros) have raised and deployed privately financed peacekeeping forces to enforce a cease-fire in Sudan. They are poised to extend the deployment of their troops to Chad and the Congo.

4. Other observations:

- Other failing African states, witnessing this intervention, outsource the majority of their principal governance functions to a Gates Foundation/McKinsey consortium led by Jeffrey Sachs.

- In parts of the Islamic world, radical parties have led revolutions, creating populist, anti-Western, capitalist regimes that are economically successful, magnets for foreign direct investment, and remain dedicated to the destruction of Israel.

- In the United States and parts of Western Europe, fully private cities that are owned, controlled, and governed by private corporations emerge to attract specific religious and cultural groups.

- By 2012, Iraq has fully disintegrated into three independent self-governing provinces. Rather than being an isolated incident, this is part of a larger trend. Who sits in Iraq's seat at the UN? Which other nations have left the UN as a result (Turkey, Iran)?

- Traditional international organizations are engaged in massive legal battles. Confusion reigns over who is empowered to sign 'treaties' and other global contractual arrangements in this world.

\section{References}

Asal, VICTOR. 2005. "Playing Games with International Relations." International Studies Perspectives 6: 359-73. Avey, Paul C., and Michael C. Desch. 2014. "What Do Policymakers Want From Us? Results of a Survey of Current and Former Senior National Security Decision Makers." International Studies Quarterly 58: 227-46.

Barma, NaAzneen, Giacomo Chiozza, Ely Ratner, and Steven Weber. 2009. "A World without the West? Empirical Patterns and Theoretical Implications." Chinese Journal of International Politics 2: 577-96.

Barma, Naazneen, Ely Ratner, and Steven Weber. 2007. "A World without the West." The National Interest 90: 23-30.

Barma, NaAzneen, Ely Ratner, and Steven Weber. 2013. "The Mythical Liberal Order.” The National Interest 124: 56-67.

Barma, Naazneen, and Rachel Whitlark. 2013. "Putting the 'Public' in Global Goods: An Empirical Investigation of Global Public Goods Provision." Paper presented at the annual meeting of the International Studies Association, San Francisco, CA.

Bleek, Philipp C., And Eric B. Lorber. 2014. "Security Guarantees and Allied Nuclear Proliferation?" Journal of Conflict Resolution 58: 429-54.

Brown, Scott, and Frederick King. 2000. "Constructivist Pedagogy and How We Learn: Educational Psychology Meets International Studies.” International Studies Perspectives 1: 245-54.

Burch, Kurt. 2000. "A Primer on Problem-Based Courses.” International Studies Perspectives 1: 31-44.

Butcher, Charity. 2012. "Teaching Foreign Policy Decision-Making Processes Using Role-Playing Simulations: The Case of US-Iranian Relations.” International Studies Perspectives 13: 176-94. 
DiCicco, Jonathan M. 2014. "National Security Council: Simulating Decision-Making Dilemmas in Real Time." International Studies Perspectives 15: 438-58.

Fearon, James D. 1991. "Counterfactuals and Hypothesis Testing in Political Science." World Politics 43: 169-95.

Feaver, Peter D. and Eric Lorber. 2014. "Penalty Box: How Sanctions Trap Policymakers." Foreign Affairs, June 6. Accessed February 28, 2015. https://www.foreignaffairs.com/articles/united-states/ 2014-06-06/penalty-box.

Fuerth, Leon S. 2011. "Operationalizing Anticipatory Governance." Prism 2: 31-46.

Gallucci, Robert L. 2012. "How Scholars Can Improve International Relations." Chronicle of Higher Education. Accessed February 28, 2015. http://chronicle.com/article/How-Scholars-Can-Improve/ $135898 /$.

George, Alexander L. 1993. Bridging the Gap: Theory and Practice in Foreign Policy. Washington, DC: United States Institute of Peace.

George, Alexander L., and Andrew Bennett. 2005. Case Studies and Theory Development in the Social Sciences. Cambridge: MIT Press.

German Marshall Fund. 2013. Post Crisis: Europe and the World in 2025-Four Foreign Policy Scenarios. Washington, DC: German Marshall Fund.

Glasgow, SARA M. 2012. "Simulating Learning by Simulating Politics: Teaching Simulation Design in the Undergraduate Context." International Studies Perspectives 15: 525-537.

Janis, Inving L. 1982. Groupthink: Psychological Studies of Policy Decisions and Fiascoes. New York: Houghton Mifflin.

Jentleson, Bruce W., and Ely Ratner. 2011. "Bridging the Beltway-Ivory Tower Gap." International Studies Review 13: 6-11.

Jervis, Robert. 1976. Perception and Misperception in International Politics. Princeton: Princeton University Press.

King, Gary, Robert O. Keohane, and Sidney Verba. 1994. Designing Social Inquiry: Scientific Inference in Qualitative Research. Princeton: Princeton University Press.

Kunn, Thomas. 1996. The Structure of Scientific Revolutions. 3rd ed. Chicago: The University of Chicago Press.

Loggins, Julie A. 2009. "Simulating the Foreign Policy Decision-Making Process in the Undergraduate Classroom." PS: Political Science Eं Politics 42: 401-407.

Mead, Lawrence M. 2010. "Scholasticism in Political Science." Perspectives on Politics 8: 453-464.

National Intelligence Council. 2008. Global Trends 2025: A Transformed World. Washington, DC: National Intelligence Council.

National Intelligence Council. 2012. Global Trends 2030: Alternative Worlds. Washington, DC: National Intelligence Council.

NyE, JosEPH. 2009. "Scholars on the Sidelines." Washington Post, April 13. Accessed February 28, 2015. http:/ /www.washingtonpost.com/wp-dyn/content/article/2009/04/12/AR2009041202260.html.

NyE, JosePh. 2005. Understanding International Conflicts. 6th ed. New York: Longman, Addison-Wesley.

PatomäкI, Негккi. 2011. "On the Complexities of Time and Temporality: Implications for World History and Global Futures." Australian Journal of Politics and History 57: 339-52.

Putnam, Robert D. 2003. "The Public Role of Political Science." Perspectives on Politics 1: 249-55.

Raskin, Paul, Frank Monks, Teresa Ribeiro, Detlef van Vuuren, and Monika Zurek. 2005. "Global Scenarios in Historical Perspective.” In Ecosystems and Human Well-Being: Scenarios_Findings of the Scenarios Working Group Millennium Ecosystem Assessment Series, edited by Stephen R. Carpenter, Prabhu L. Pingali, Elena M. Bennett, and Monika B. Zurek. Washington, DC: Island Press.

Rothman, Steven B. 2008. "Comparatively Evaluating Potential Dissertation and Thesis Projects." PS: Political Science Eै Politics 41: 367-69.

Rothman, Steven B. 2012. "Developing and Adapting Simulations through Six Points of Variance: An Example of Teaching Applied Game Theory through International Negotiations." International Studies Perspectives 13: 437-57.

Sagan, Scott D., and Kenneth N. Waltz. 2003. The Spread of Nuclear Weapons: A Debate Renewed. New York: W.W. Norton.

Schwartz, Peter. 1991. The Art of the Long View: Planning for the Future in an Uncertain World. New York: Doubleday.

Tetlock, Philip E. 2005. Expert Political Judgment: How Good Is It? How Can We Know? Princeton: Princeton University Press.

Useem, Bert. 1997. “Choosing a Dissertation Topic.” PS: Political Science E Politics 30: 213-16.

Van Evera, Stephen. 2010. "Director's Statement: Trends in Political Science and the Future of Security Studies." In Massachusetts Institute of Technology Security Studies Program Annual Report 2009-2010. Cambridge: Massachusetts Institute of Technology. 
WACK, Pierre. 1985. "Scenarios: Shooting the Rapids-How Medium-Term Analysis Illuminated the Power of Scenarios for Shell Management." Harvard Business Review (November-December 1985): 139-50.

Walt, Stephen M. 2005. "The Relationship between Theory and Policy in International Relations." Annual Review of Political Science 8: 23-48.

Walt, Stephen M. 2009. "The Cult of Irrelevance." Foreign Policy, April 15. Accessed February 28, 2015. http://www.foreignpolicy.com/posts/2009/04/15/the_cult_of_irrelevance.

Walt, Stephen M. 2011. International Affairs and the Public Sphere. Faculty Research Working Paper Series RWP11-030. Cambridge: Harvard Kennedy School.

Weber, James. 1992. "Scenarios in Business Ethics Research: Review, Critical Assessment, and Recommendations." Business Ethics Quarterly 2: 137-60.

Wielhouwer, Peter W. 2004. "Teaching Campaign Ethics Using Web-Based Scenarios.” PS: Political Science E Politics 37: 865-869.

Wilkinson, Angela, and Roland Kupers. 2013. "Living in the Futures-How Scenario Planning Changed Corporate Strategy.” Harvard Business Review (May 2013): 3-11. 